\title{
The burden of choice: a qualitative study of healthcare professionals' reactions to ethical challenges in humanitarian crises
}

\author{
Sarah Gotowiec ${ }^{1,2^{*}}$ (D) and Elizabeth Cantor-Graae ${ }^{2}$
}

\begin{abstract}
Healthcare professionals are a vital aspect of public health delivery in humanitarian crises. Both overt and subtle complexities in the decision making process during periods of instability may involve moral and ethical considerations. Few studies have examined the lived experiences of healthcare professionals encountering ethical challenges in the field. The aims of this qualitative study were to explore how healthcare professionals perceive complex ethical choices and to understand the impact these challenges had on them both personally and professionally. The data was analyzed using manifest and latent qualitative content analysis. Four themes emerged from the data analysis: ethics as a sense of right or wrong, adversely bearing the burden of choice, held hostage by institutional constraints, and the difficulty of preparing for ethical challenges. The overarching theme struggling to make the right choice established that ethical challenges created difficulties for healthcare professionals both in negative psychological outcomes and the perception of reduced patient care. Awareness of these ethical challenges can help organizations to fully support healthcare professionals in the field to reduce personal struggles and provide optimal care delivery.
\end{abstract}

Keywords: Humanitarian crises, Ethical challenges, Moral distress, Healthcare professionals

\section{Background}

Humanitarian crises $(\mathrm{HCs})$ are dynamic catastrophes that can burden local systems to the point of collapse. In the current global context, HCs both manmade and natural are highlighted in the realm of international public concern. The healthcare aspect of the response to HCs is most effective when built on models of public health intervention, for example, a strong emphasis on disease prevention and health promotion (Brennan and Nandy 2001). For this reason, there is the direct and necessary involvement of public health delivery systems in times of $\mathrm{HCs}$. International public health response in an $\mathrm{HC}$ is often provided by humanitarian organizations in all periods of an intervention: disaster relief, rebuilding, and development stages (Chung 2012). Humanitarian organizations send healthcare professionals (HCPs) to provide

\footnotetext{
* Correspondence: s.gotowiec@psy.au.dk

'Department of Psychology and Behavioral Sciences, Aarhus University, Bartholins Alle 9, 8000 Aarhus C, Denmark

${ }^{2}$ Department of Social Medicine and Global Health, Lund University, CRC Jan Waldenströms gata 35, 20502 Malmö, Sweden
}

care in contexts where there are often disparities between what is needed and the care that HCPs in the field are able to provide.

Many factors innate to the environment in HCs affect the work, including scarcity of resources, security issues, overwork, inter-personal issues, lack of preparation, and perceived lack of appreciation from victims (Bjerneld et al. 2004). Many HCPs report depression, helplessness, anxiety, burnout, and further psychological distress and sleep disturbances upon returning home (e.g., Lopes Cardozo et al. 2012; Walsh 2009; Ager et al. 2012). HCPs recognize that one's personal characteristics can influence field experiences, particularly in regards to decision making. Characteristics such as personality, mental stability, reasons for going on the mission, and ability to work as a team member may factor into the decisions that are made in the field (Bjerneld et al. 2004; Thoresen et al. 2009).

Recent years have brought an increasing discourse regarding the moral issues encountered in decision making in humanitarian crises. For a decision to be in the ethical dimension, it is not necessary that the resulting decision 
is consistent with ethical norms (Jones 1991). It simply means that the individual is presumed to recognize that there are moral considerations involved in the presented choices (Nilsson et al. 2011). The term "moral dilemma" is defined as a decision where any possible choice will conflict with an existing moral principle (Blackburn 1994). At times, tough or hellish choices can masquerade as moral dilemmas (Slim 1997). For the purpose of this article, the authors have operationalized the term "ethical challenges" to encompass situations faced when the HCPs perceived themselves to be confronted by decisions that called upon their ethical principles in a problematic manner. The term "dilemma" is used when referencing previous work that utilized this term.

Research in the study of ethical decisions specific to HCPs performing humanitarian work is an emerging and interdisciplinary field. Slim's (1997) seminal paper acknowledged the demanding moral choices being faced by both humanitarian agencies and their staff and outlined guidelines for confronting these moral dilemmas. However, in the time since Slim's paper was published almost two decades ago, there has been a scarcity of research that focuses specifically on the lived experience of HCPs who have grappled with decisions in the ethical realm while on an assignment (Nilsson et al. 2011). Topics that have been explored since include: the impact of fieldwork on the physical and mental health of relief workers (e.g., Bjerneld et al. 2004; Lopes Cardozo et al. 2012; Ager et al. 2012), the ethics of both humanitarian aid work and ethical issues encountered in the actual work (e.g. Hunt et al. 2011; Nilsson et al. 2011; Schwartz et al. 2010, 2012), and qualitative studies on HCPs' individual experiences of stress in the field (Bjerneld et al. 2004). The present study aims to expand this underdeveloped stream of inquiry.

There are multiple international codes of ethics to guide HCPs in their work (i.e., Statement On Medical Ethics In The Event Of Disasters, World Medical Association 2006; United Nations Draft Declaration on Bioethics and Human Rights, UNESCO 2005; The Sphere Project Humanitarian Charter and Minimum Standards in Humanitarian Response 2010). However, there is no overarching system of rules to govern which set of guidelines to follow (Schwartz et al. 2012). There can be conflict between individual and institutional codes of ethics, which in turn intersects with clinical ethics and public health ethics. Tension between clinical and public health ethical ideologies is created because of the different focus of each of the following: individual good versus the focus on the greater good and social justice (Schwartz et al. 2012). The individual needs ingrained in clinical codes of ethics cannot necessarily exist harmoniously with the population-based principles of public health care. Navigating these choices has been identified as a source of confusion and challenge (Schwartz et al. 2012). Compounded by a lack of resources in the field, these decisions can turn into dilemmas where there is no clear "right" choice (Jameton 1984).

HCPs encounter situations demanding immediate decisions, yet have very little training, standardized guidance, or ethical support structures. Four main sources of ethical dilemmas in the field were reported by Schwartz et al. (2010): (i) allocating scarce resources, (ii) navigating existing socio-political landscapes, (iii) the policies and agendas of aid organizations, and (iv) the norms surrounding fieldworkers' roles and interactions. Other sources of dilemmas include difficulties in adhering to cultural contexts, acknowledging imbalances of power, encountering organizational barriers to provision of care, lack of regulatory standards, and individual differences in understanding of health and illness (Hunt 2008, 2011; Nilsson et al. 2011). HCPs have identified that the burden of responsibility that accompanies these decisions to be highly stressful (Schwartz et al. 2010). The effect on individuals who must make ethical decisions in uncertain environments can be both personal and professional. These challenges can be a cause of self-reflection, questioning of personal identity, and alteration of selfidentification as a moral person (Hunt et al. 2011). This issue extends to professional identity when HCPs must perform actions that do not necessarily lie within the boundaries of their usual professional duties or are prevented from delivering care as they would do in their home context (Hunt 2008). The outcome of all of these different pressure points can be distress, anxiety, uncertainty, and remorse (Hunt et al. 2011; Nilsson et al. 2011).

The negative psychological outcomes from ethical dilemmas are one category that can be the cause of "moral distress". This term is defined as the painful psychological dissonance that happens when one is forced by external institutional constraints to carry out actions that are not in accordance with one's internal moral compass (Jameton 1984). This definition was extended by Kälvemark et al. (2004) to include external constraints beyond those at the organizational level. Most previous research in this area has investigated moral distress in the context of nurses (Kälvemark et al. 2004). The study of moral distress in humanitarian HCPs is a relatively new field.

Another model related to ethical dilemmas is Raines' (2000) "ethics stress model" which explains the association between moral analysis, individual coping mechanisms, and the level of stress perceived when one must make ethical decisions. The model is an extension of Jameton's (1984) three stages of ethical decision making: moral uncertainty, moral dilemma, and moral distress. Paired together, the ethics stress model and moral distress theories can shed some light on the negative stress symptoms associated with ethical challenges in HCs. Both models build on the presupposition that HCPs endeavor to act in an ethically responsible manner in their 
professional lives (Kälvemark et al. 2004). Being constrained by external limitations that prevent an HCP from working in a manner they deem personally ethical has been shown to manifest in frustration, anger, anxiety, guilt, remorse, and fear (Kälvemark et al. 2004; Radzvin 2011). These symptoms contribute to headaches, feelings of worthlessness, burnout, and a feeling of loss of moral identity (Radzvin 2011). As a result, HCPs may feel unable to provide care using best practices.

Few studies have explored the experiences of HCPs with regard to how they perceive ethical challenges encountered in the field and how they are influenced by these conflicts. The overall objective of this study was to gain a deeper understanding of the experiences of humanitarian HCPs' encounters with ethical challenges during the course of their field engagement. The specific aims were (i) to explore how HCPs perceive ethical challenges and (ii) to explore the effect these challenges had on them both personally and professionally.

\section{Methods}

A qualitative research design used data from eight indepth interviews with HCPs who had participated in fieldwork during any stage of an HC. A semi-structured interview format allowed the participant to describe their lived world (Kvale and Brinkmann 2009).

\section{Sampling}

Participant selection began purposively with the distribution of an information sheet through contacts at several humanitarian aid organizations. Snowball sampling was used to recruit additional participants. The sampling strategy aimed to maximize diversity of experiences, through breadth of public health roles, variety of organizations included in the sample, and participation in different types and stages of HCs. The data was collected as part of a master's thesis project, and time constraints meant that sampling was restricted to eight participants. Furthermore, the authors noticed a repetition of themes beginning with the seventh interview. However, this possible limitation is further addressed in the "Methodological considerations" section. The criterion for inclusion was previous or ongoing participation in an $\mathrm{HC}$ in the capacity of service delivery as a HCP. The participants worked with a number of different organizations, ranging in size from regional NGOs to international humanitarian institutions. Collectively, they had worked with 15 different organizations in a diverse range of public health roles as nurses, medical doctors, heads of mission, area safety officers, and anesthesiologists. Many of the participants had responsibilities in both management and patient care. The HCs were times of war, natural disaster, epidemics, and political turbulence in geographic areas spread across Africa, the Middle East and the Caribbean.
The missions were mainly in the disaster relief and rebuilding stages, and one participant had also worked in the development stage. The participants ranged in age from 28 to 69, with careers in humanitarian action spanning between 2 and 20 years. Each individual had completed their most recent mission within the last 2 years. All interactions with participants were conducted in rigorous accordance with ethical guidelines governing research on human subjects, i.e., informed voluntary consent, anonymity, and confidentiality. The regional ethics review board required no formal ethical permission, as the project was a master's thesis project and complied with institutional ethical requirements.

\section{Data collection}

An interview guide was created solely for this study. The questions were open ended with individually adapted follow-up probing questions. Introductory questions asked for basic personal data, including age, educational level, current occupation, and the nature of their work in HCs. Participants were then asked to reflect on their conception of ethics, the times they had experienced ethical challenges and their reactions, and their thoughts on their preparation for situations of this nature.

The principal researcher carried out every interview in English. One face-to-face interview was conducted in Malmö, Sweden, and seven were conducted via Skype due to the geographical locations of the participants. Each conversation was recorded, and field notes were taken to supplement the recordings. The interviews lasted between 38 and $58 \mathrm{~min}$, and no reimbursement was offered for participation.

\section{Data analysis}

The data was analyzed following the manifest and latent qualitative content analysis approach outlined in Graneheim and Lundman (2004). The interviews themselves were the units of analysis, which were then sectioned into condensed meaning units. The condensed meaning units were entered into a Microsoft Excel spreadsheet and labeled with codes. Next, a manual technique was used to group together codes into subcategories, and then categories. The categories were grouped together to yield emergent themes. Finally, an overarching theme was identified using the codes, subcategories, categories, and themes (see example, Table 1).

\section{Results}

The overarching theme struggling to make the right choice is reflected in all of the themes that emerged from the data analysis. There were different perspectives expressed about participants' individual definitions of ethics and morals but the general view was that they were decisions between right and wrong. The participants shared that 
Table 1 Example of the coding process

Meaning unit:

Condensed meaning unit:

Codes:

Categories:
I think, first of, there is the huge amount of sadness, to, to, know that you are there, and you have quite good financial possibilities behind you of trying to help the people that are there, and your hands are tied from doing anything but sending a person back to, this bad situation they are in.

There is a huge amount of sadness, to know you are there with good financial possibilities and your hands are tied from doing anything but sending a person back to a bad situation.

1: Feeling deep sadness

2: Feeling forcibly restrained

3: Being prevented from the right action

1: Experiencing emotional suffering

2: Struggling against orders

3: Experiencing emotional suffering doing the right thing was motivated by an innate sense of justice that guided them both personally and as medical professionals. However, they felt that they were sometimes unable to follow through on actions they deemed ethically correct. With little or no training in ethical action in the field, the participants needed to make decisions that balanced the needs of the patients, organizational politics, and cultural contexts. The issues in this domain that were unique to HCs added a layer of complexity to the struggle to make the right choice. As a result the participants were affected both from negative psychological feelings and from feelings of reduced patient care as a result of being put in the situation of ethical challenges. The results explore the following themes: ethics as a sense of right or wrong, adversely bearing the burden of choice, held hostage by institutional constraints, and the difficulty of preparing for ethical challenges (see Table 2).

\section{Theme \# 1: Ethics as a sense of right or wrong}

All participants recognized an innate sense that ethical choices are polarized between "right" and "wrong". The sensation of right or wrong was voiced as a simple feeling. There were different views on where their moral compass came from, including from parents, religion, and a feeling of responsibility towards helping others as a part of their professional duty. Participants experienced and explained ethical challenges that had happened between the self and organization, challenges within the self, and challenges between the self and culture. For instance, participants were hesitant to violate individual clinical ethics in service of upholding institutional guidelines and this made them unsure of which values to apply in a given situation. Participants described the psychological tension that arose when their organization's needs were not aligned with the needs of their patients:

Table 2 Results from the data analysis displaying the organization of the overarching theme, themes, categories, and subcategories

\begin{tabular}{|c|c|c|}
\hline Overarching theme & Themes & Categories and subcategories \\
\hline \multirow[t]{4}{*}{ Struggling to make the right choice } & 1. Ethics as a sense of right or wrong & $\begin{array}{l}\text { Experiencing various ethical challenges } \\
\text { Challenges between self and organization } \\
\text { Challenges within self }^{\mathrm{b}} \\
\text { Challenges between self and culture }^{\mathrm{b}} \\
\text { Wanting to do the right thing } \\
\text { Recognizing unethical motivations }\end{array}$ \\
\hline & 2. Adversely bearing the burden of choice & $\begin{array}{l}\text { Experiencing emotional suffering } \\
\text { Powerlessness and instability } \\
\text { Anger and frustration } \\
\text { Being isolated and abandoned } \\
\text { Sadness } \\
\text { Negative impacts on care delivery } \\
\text { Not wanting to continue } \text { work }^{\mathrm{a}} \\
\text { Needing coping mechanisms } \\
\text { Needing to be tough }\end{array}$ \\
\hline & 3. Held hostage by institutional constraints & $\begin{array}{l}\text { Being silenced by the organization }{ }^{a} \\
\text { Organization feigning ignorance } \\
\text { Bureaucracy as an } \text { alibi }^{\mathrm{a}} \\
\text { Struggling against orders }\end{array}$ \\
\hline & 4. The difficulty of preparing for ethical challenges & $\begin{array}{l}\text { Lacking formal ethical guidelines }{ }^{\mathrm{a}} \\
\text { Questioning how to train for challenges } \\
\text { Looking for guidance from the team }^{\mathrm{a}} \\
\text { Experience making it easier }^{\mathrm{a}} \\
\text { Positive organizational support }\end{array}$ \\
\hline
\end{tabular}


When you are a doctor in the field you try as best as you can to follow the programmatic choices but when it comes into conflict with your own values, well-you disregard them...the fighting always creates residual resentments, or grudges, or destroys the team dynamics, so that is not an easy decision to oppose the programmatic decisions of your organization. (P4)

The participants expressed challenges within the self when they were unsure of which values to apply in a given situation. Uncertainty can be created when one is hesitant about crossing professional ethics guidelines. Furthermore, challenges arose from differences in environment between the HCP's home and the cultural context encountered in HCs, when something defined as "wrong" according to the individual might be defined as "right" in the HC context. There were also conflicts when working in teams that were comprised of workers from different nationalities. Participants tried to prioritize helping others over adhering to rules that were born in their home countries. But this meant that at times, participants felt it was necessary to compromise their own morals in order to accommodate and acknowledge a different cultural context. One example was when a participant saw that the local practice would harm more people than the technique that the $\mathrm{HCP}$ was trying to instill, after they unsuccessfully tried to promote safe water sanitation techniques in a field hospital:

Then you just kind of have to find out the way that is the best in that situation, it can be wrong if you look at it from your background, but in that situation it is probably the best that you can do. (P2)

The HCPs talked about wanting to do the right thing. Participants felt that their innate values caused them to prioritize helping others. The sensation of right or wrong was voiced as a simple feeling. It extended beyond borders and touched upon shared humanity. This feeling allowed the participants to rise above the struggles and hurdles posed by the challenges they encountered in the field and demonstrate strength and courage. This sense of strength and courage underlies many of the stories related by the participant. One participant shared the view:

It is about the other person, and you know, treating your peers as you would like to be treated yourself. I think that this is something that probably has a common ground with any culture or religion where there is a common ground of humanity. (P7)

\section{Theme \# 2: Adversely bearing the burden of choice} This theme describes emotional suffering that emerged during and after decisions that became ethical challenges.
The inescapable feelings of stress were experienced both psychologically and professionally. Participants ruminated over these decisions both during the actual experience and then continued to have vivid memories after they left the field. They reflected on the personal impact of encountering ethical challenges, for example, when one HCP was forced to prioritize the care of one of two equally sick children. The participant recalled the somatic problems they experienced afterwards:

Sleeping difficulties I guess. And that is something that I never get, unless in very severe situations. Sleeping difficulties, eating difficulties. Like, we spent days without eating because you just can't even swallow your own saliva. It's just, you can't even breathe normally. (P8)

Two of the most prominent post-decision making feelings were powerlessness and instability. Being in an unpredictable environment required HCPs to adjust to the idea that many issues were beyond their influence. The feelings of helplessness led to feelings of anger and frustration. Emotions ranged from short-term irritation to long-lasting outrage and cynicism. Participants also shared feelings of being isolated and abandoned after having to make difficult ethical decisions. The perception of isolation was geographical and also psychological abandonment by leadership and peers. There were feelings of deep loneliness and of being unable to cope alone. One participant recounted their reaction after they perceived that their organization would not support them while confronting an ethical challenge regarding the disposal of deceased bodies following an earthquake:

And it made me angry and it made me feel actually more isolated and alienated, in general. (P1)

Feelings of sadness and despair were also prominent. Different expressions of this emotion included distress, remorse, hopelessness, and devastation during times when the HCPs felt ethically constrained in decision making:

So it is the same type of emotion, just from a different aspect of frustration, of helplessness of trying to get other people to work, trying to find somebody who can to help you in the situation but it was both like a moral dilemma and a lot of sadness. (P6)

The participants felt that there were negative impacts on care delivery. Experiences included being prevented by organizational directives from continuing care or being so distressed by ethical challenges that the HCP felt their professional abilities were impeded. The emotional stress of experiencing ethical challenges and the impact 
these negative feelings had on the HCPs' ability to provide care led to many participants expressing that they did not want to continue working. One participant was forbidden from acknowledging a public health epidemic because their organization refused to jeopardize their relationship with the government in the relevant country. The participant shared:

This very easy and cheap intervention was denied because the mere fact to conduct this intervention would make it clear to the public and to the authorities that something was wrong in detention... I would say anger, tiredness, and I ended up the terms of my mission that I didn't want to come back. (P4)

To deal with the psychological burden of ethical challenges, numerous participants coped by shutting off emotionally or by putting up barriers between themselves and the patients with whom they felt guilt towards. However, it is important to note that the participants showed courage and strength in facing these tough situations. They identified that they needed to be tough and fight to find emotional stability from within. The motivation to find the toughness within seemed, in part, to come from the drive to deliver the best healthcare possible in accordance with their professional duties, but also from their personal sense of right and wrong.

\section{Theme \# 3: Held hostage by institutional constraints}

This theme emerged from situations HCPs encountered when they were inhibited by their organizations. The general view was that the geographical distance between the local team and the head office created distance from feelings of separation and remoteness. The participants shared that they felt at times that they were being silenced by their organizations or implicitly told to turn a blind eye to the real situation at hand, leaving them unable to proceed in what they felt was an ethical manner. The directive from their organization to "keep a low profile" haunted one of the participants:

From the [organization's] side...people agreed it was the right diagnosis, but there was nothing they could do to help me do the right public health action. And, one typical answer that I got, I will always remember this, was "keep a low profile". (P4)

The HCPs also related perceptions about when their organization was feigning ignorance. Participants talked about a variety of times when they witnessed their superiors refusing to accept responsibility for the problems being encountered at a local level. However, often the HCPs would try to reason through the situation; reflecting and analyzing what was happening at the organizational level. They displayed strength by rising above situational pressures and continuing the mission, even once they understood what was happening:

So that's my analysis, that it could be the consequence of lack of information or ignorance. Or sometimes it could be deliberate. We don't want to know about that. We don't want to know about the uncomfortable truth. (P4)

The forced silence meant that HCPs were forced to juggle decisions that balanced ethical action at the personal and field levels with orders from their managers. When the head office was perceived as hiding behind regulations and rules, participants felt that their organizations were using bureaucracy as an alibi. Situations of this nature included the HCPs in the field being obligated to follow orders that forced them to act in conflict with their individual clinical ethics. The inaction by a head office perceived by the HCPs forced them into ethical challenges and created feelings of helplessness, victimization, and a lack of loyalty. They felt backed into making choices that were not in line with their moral compass, for instance, when this participant's head office would not allow them to change the contractor for a hospital building site even though the contractor was not using high-standard building materials:

And it was just like a year of, basically, inaction from head office and they were burying their head in the sand and not dealing with it. [...] So I have learned to make moral compromises, and I would like to think on the serious ones that I would not accept it, but, who knows. (P5)

\section{Theme \# 4: The difficulty of preparing for ethical challenges}

There is a difficult task in preparing for ethical decisions in the field. Choices that invoke ethical reasoning are acknowledged to be abstract, and it is challenging to provide a comprehensive preparatory package for HCPs. The general perception from the participants was that they were lacking concrete ethical guidelines for fieldspecific situations:

Medically, there are guidelines and there are medical ethics where we are bounded to within the hospital. We have to do this and this and that, and those ethics are clear, and we are trained to use them and to apply them...I just think that there should be a set of guidelines within a catastrophe situation. And there is not. They are very vague and we are not trained about them. (P8) 
Some participants felt that having formal training and guidelines for ethical challenges would be impossible. Others thought that a syllabus of scenarios and protocols that could be discussed pre-departure would be very helpful:

I don't think I was very well prepared...well I am not even sure you can go and have a course, of course you can be presented with potential situations or problems but I think once you are in the specific situation...then it is very difficult. (P6)

Lacking formal preparation for encountering ethical decision making in the field, HCPs were compelled to look for guidance from the team. Consulting with peers gave participants a safe space in which to explore options for action and feel the support that they were lacking from their organization, and the participants did not favor situations where this peer support did not exist. Discussing ethical dilemmas was identified as a favored way of finding reinforcement in the field. This also created a feeling of camaraderie and helped to dispel the isolated feelings expressed by some participants:

I think it is basically through talking with your peers and colleagues who have been through the same thing. Almost always with other [...] colleagues who have been through the same thing. (P7)

Prior encounters with ethical challenges allowed HCPs to learn how to adjust to new cultural contexts, learn the practical aspects of working in the field, and be taught how to navigate issues of right and wrong in an HC. The HCPs learned more with each mission about how to creatively respond to new situations and learn from their surroundings. One participant elaborated:

Experience helps a lot. And of course, if you are interested in different cultures, and you want to read and you have a good contact with local people...you can understand better how they think and all this. So I think that comes with the experience. (P2)

Participants acknowledged that at times they did receive positive organizational support. When they felt that their opinions were valued by their organizations, participants said that the psychological effect from ethical challenges in the field was eased. Having a supportive foundation made participants feel more prepared, and as though they had an external guide to rely on once they were in the field:

I guess there would be other dilemmas where...we succeed and overcome those boundaries...Once again
I am quite happy and quite lucky working within the [organization's] structure because we have those kind of foundations upon which we are working. (P7)

\section{Discussion}

The aims of this qualitative study were to explore how HCPs perceive ethical challenges and to understand the impact that these challenges had on them both personally and professionally. This study demonstrates that HCPs are affected by ethical challenges in emotionally stressful ways that can have an adverse impact on their ability to deliver care. The themes that emerged agree with and expand on earlier findings about the perceptions of ethical challenges in humanitarian aid work. It is important to recognize how HCPs conceive ethics in order to be able to fully understand their experience of ethical challenges. The findings revealed that ethics is a diffuse concept. Individuals identified a strong inner sense of right and wrong as opposed to an explicit definition of what ethics are. The participants indicated that this sense was not necessarily overtly taught but instead instilled in them throughout their lives and experiences. They used their personal values as a moral guide in times of decision making.

Previous research focused on understanding the nature of ethical dilemmas and the moral reasoning employed by HCPs (e.g., Schwartz et al. 2010). The current study identified similar findings, specifically challenges between oneself and the organization, oneself and the cultural context in the $\mathrm{HC}$, and internally within oneself. All of these experiences shared a core of personal conflict. The struggle was a result of the individual's conception of their ethics interacting with the complex institutional, cultural, and personal environments in HCs. Studies have shown that HCPs who have encountered ethical dilemmas experienced symptoms of anxiety, distress, uncertainty, and remorse (Hunt et al. 2011; Nilsson et al. 2011). The findings in this study are strikingly similar. Participants elaborated on a variety of emotional suffering. They recounted a range of feelings including helplessness, outrage, abandonment, and despair.

The study identifies that the negative feelings being reported are indicative of moral distress. Previously, Kälvemark et al. (2004) built on Jameton's (1984) definition of moral distress to encompass the negative symptoms of psychological dissonance when one is forced by external restrictions to carry out actions that do not align with one's internal moral compass. One study (Nilsson et al. 2011) discussed moral distress in humanitarian aid operations, but otherwise, this concept has previously been researched mainly in the field of nursing and healthcare professionals in formal workplaces (e.g., Kälvemark et al. 2004; Radzvin 2011). Moral distress, combined with Raines' (2000) model of stress related to 
ethical decision making, can help explain the profound negative feelings expressed by the participants. Further research into the area of ethical challenges and the resulting moral distress in $\mathrm{HCPs}$ in $\mathrm{HC}$ environments could focus more extensively on the context of the variety of ethical issues being encountered (Kälvemark et al. 2004). This area of inquiry will be beneficial to understanding how HCPs can be more effectively supported in order to avoid negative reactions.

The current study brought to light new ideas about how ethical challenges can be linked to barriers to care. The problem of whether the HCP or their organization should bear the burden of responsibility in ethical dilemmas has previously been commented on (Schwartz et al. 2012). The participants in this study believed that the organizations sometimes prioritized political or institutional agendas over the individual patient. This resulted in the prevention of proper care delivery. This lack of support is a problem that affects the individual both personally and professionally. The negative psychological symptoms experienced in times of moral distress also negatively impacted service. HCPs who were not at their full psychological fitness felt impeded from acting to the fullest of their professional abilities. Participants also identified that after experiencing ethical challenges, they felt resistance to continuing on the mission or working again with their organization. Their experiences affect both optimal public healthcare delivery in HCs and the individual abilities of the HCPs as public health workers.

Previous research has discussed different frameworks and guidelines for approaching ethical dilemmas in the field (Hunt 2011; Hunt et al. 2011). The findings in this study are similar to previous research indicating that ethical challenges are complex situations and therefore institutional guidance is also a complex task. As ethics is an abstract concept, the benefits of including theoretically oriented preparation for ethical dilemmas prompted skepticism from the participants in Hunt et al. (2011). The individuals in this study expressed the same opinions. It was expressed that tools need to be developed are those relevant to the environment in HCs. Developing a comprehensive case-based preparatory package using research findings could help to make HCPs aware of the issues that exist, culturally, politically, and socially (Hunt et al. 2011). For instance, individuals could be made aware of the tension between individual clinical ethics and public health care ethics that exists in HCs (Schwartz et al. 2012). It was expressed previously (Hunt et al. 2011) and in this study that peer support from the local team can help mitigate the stress reaction. Therefore, scheduled team meetings during the mission dedicated to discussing issues related to ethical decision making (both before and after) could be a valuable tool in helping HCPs move through these issues and process the psychological impact. While pre-departure training tools may help to prepare HCPs, a framework for guidance and support during the actual mission may be the most beneficial tool to develop.

One aspect of the findings goes beyond the need for organizations to provide training or support for HCPs. It relates to a deeper issue of organizational ethos and expresses the urgent need for humanitarian organizations to admit to and address the direct impact of ethical challenges on HCPs in the field. This is highlighted by the participants' commonly shared experience of being "held hostage by institutional constraints." The current study extends the previous discussion on this issue (Schwartz et al. 2010; Hunt 2008) by elaborating on multiple ways that participants felt their organizations were restricting them: feigning ignorance, silencing them, and hiding behind bureaucracy. HCPs in the current study struggled with feelings of being silenced and ignored by their organization when they reached out for help and guidance in times of ethical challenges. As a result, participants commonly had strong and long-lasting negative emotions towards the organizations they worked for and expressed that they no longer wanted to go on missions in the field.

These findings suggest that organizations have an imperative to address the ways that they both cause and exacerbate ethical challenges experienced by HCPs. Turning a blind eye to ethical issues in the field does not remove an organization's culpability for their actions. The "feigning of ignorance" allows an organization to make public programmatic decisions that are ethically responsible while at the same time putting their workers in the position of encountering ethical challenges in the field. This raises the issue that for an organization to support their HCPs to the fullest, they must also admit that moral distress is a real issue. There is a rather large challenge of first having humanitarian organizations admit that the guidelines regarding their boundaries of moral responsibility do not necessarily encompass all of the applied decision making in the field. The authors suggest that the first step in the right direction would be to further understand the nature of how organizations respond to ethical challenges in the field and the negative fallout from the burden of these choices on HCPs.

This study achieved its main objective of evolving an understanding of how HCPs perceive ethics and ethical challenges, and the impact that these issues have on them. Understanding moral distress as related by HCPs is the first step to understanding how the negative reactions can be alleviated. Being able to identify the ethical challenges experienced by HCPs and the impact they feel from them will assist organizations to plan suitable frameworks for training and guidance in ethical challenges. This will offer improved support for their HCPs 
and in turn improve public healthcare provision in the time of HCs. However, first humanitarian aid organizations must recognize the role they play in creating issues surrounding ethical decision making, in order to ever be able to fully support their workers. To build on this study, the next step would be to discuss these issues with a larger cohort of participants in order to gain an understanding of a wider range of experiences and perceptions in these topics.

\section{Methodological considerations}

One possible limitation of the current study is the use of Skype interviews. After the discussion between the coauthors, it was determined that accessing a wide variety of experiences was more important than being limited by geographical constraints. Deakin and Wakefield (2014) identify that Skype interviews allow for increased flexibility and equivalent rapport-building with participants. Another limitation is inherent in the nature of the study design, which included HCPs from a variety of roles and HCs. Further research could pinpoint specific stages of $\mathrm{HCs}$ and narrow down specific ethical challenges encountered in each. The small sample size was another limitation, including the snowball method of sampling, which could mean that individuals with similar views may be more likely to be recruited. Furthermore, the participants in the present study were all expatriate HCPs, which means that the voices of local HCPs native to the countries affected by the $\mathrm{HC}$ are excluded. A future, expanded project with a larger sample size including non-expat participants is important. By interviewing individuals with a variety of roles from an array of organizations, the authors hoped to reduce this limit. Further qualitative in-depth study into this topic with a larger and more varied sample size is a direction for future research.

\section{Conclusion}

Comprehensive public health response during $\mathrm{HCs}$ often requires the assistance of HCPs from external organizations. These workers must deal with constraints from both their administrations and the resource-scarce environment. Research has begun to explore the field of ethical dilemmas and challenges in healthcare work in HCs. This study indicates that HCPs in HCs experience ethical challenges in a variety of ways and that they feel negatively impacted both personally and professionally by these conflicts. More research is needed that deepens an understanding of the perceptions of the ethical decision making experienced by HCPs in HCs and the feelings of moral distress they experience as a result. This will assist in developing tools to prepare for and respond to these situations encountered in the field in a way that supports HCPs both psychologically and in care delivery. Public health service provision in HCs will be positively impacted if the HCPs that deliver care are able to work at their optimal capacity.

\section{Acknowledgements}

We thank the participants in this study who willingly shared their experiences and thoughts.

\section{Funding}

This work was not supported by any funding bodies.

\section{Authors' contributions}

Both authors designed the study together. SG carried out the literature review and data collection. SG led the data analysis and preparation of the manuscript with support, editing and input from ECG. ECG provided a critical review of the manuscript. Both authors read and approved the final manuscript.

\section{Competing interests}

The authors declare that they have no competing interests.

Received: 21 October 2016 Accepted: 26 January 2017

Published online: 08 February 2017

\section{References}

Ager A, Pasha E, Yu G et al (2012) Stress, mental health, and burnout in national humanitarian aid workers in Gulu, Northern Uganda. J Trauma Stress 25:713-720. doi:10.1002/jts.21764

Bjerneld M, Lindmark G, Diskett P, Garrett M (2004) Perceptions of work in humanitarian assistance: interviews with returning Swedish health professionals. Disaster Manag Response 2:101-108. doi:10.1016/j.dmr.2004.08.009

Blackburn S (1994) The Oxford dictionary of philosophy. Oxford University Press, Oxford

Brennan R, Nandy R (2001) Complex humanitarian emergencies: a major global health challenge. Emerg Med Australas 13:147-156. doi:10.1046/j.1442-2026. 2001.00203.x

Chung R (2012) A theoretical framework for a comprehensive approach to medical humanitarianism. Public Health Ethics 5:49-55. doi:10.1093/phe/phs001

Deakin H, Wakefield K (2014) Skype interviewing: reflections of two PhD researchers. Qual Res 14:603-616. doi:10.1177/1468794113488126

Graneheim U, Lundman B (2004) Qualitative content analysis in nursing research: concepts, procedures and measures to achieve trustworthiness. Nurs Educ Today 24:105-112. doi:10.1016/j.nedt.2003.10.001

Hunt M (2008) Ethics beyond borders: how health professionals experience ethics in humanitarian assistance and development work. Dev World Bioeth 8:59-69. doi:10.1111/j.1471-8847.2006.00153.x

Hunt M (2011) Establishing moral bearings: ethics and expatriate health care professionals in humanitarian work. Disasters 35:606-622. doi:10.1111/j.14677717.2011.01232.x

Hunt M, Schwartz L, Elit L (2011) Experience of ethics training and support for health care professionals in international aid work. Public Health Ethics 5:91-99. doi:10.1093/phe/phr033

Jameton A (1984) Nursing practice. Prentice-Hall, Englewood Cliffs

Jones TM (1991) Ethical decision making by individuals in organizations: an issue-contingent model. Acad Manage Rev 16:366-395

Kälvemark S, Höglund A, Hansson M et al (2004) Living with conflicts-ethical dilemmas and moral distress in the health care system. Soc Sci Med 58: 1075-1084. doi:10.1016/s0277-9536(03)00279-x

Kvale S, Brinkmann S (2009) InterViews. Sage Publications, Los Angeles

Lopes Cardozo B, Gotway Crawford C, Eriksson C et al (2012) Psychological distress, depression, anxiety, and burnout among international humanitarian aid workers: a longitudinal study. PLoS ONE 7:e44948. doi:10.1371/journal. pone.0044948

Nilsson S, Sjöberg M, Kallenberg K, Larsson G (2011) Moral stress in international humanitarian aid and rescue operations: a grounded theory study. Ethics Behav 21:49-68. doi:10.1080/10508422.2011.537570

Radzvin L (2011) Moral distress in certified registered nurse anesthetists: implications for nursing practice. AANA J 79:39-45

Raines ML (2000) Ethical decision making in nurses: relationships among moral reasoning coping style, and ethics stress. JONAS Healthc Law Ethics Regul 2:29-41

Schwartz L, Sinding C, Hunt M et al (2010) Ethics in humanitarian aid work: learning from the narratives of humanitarian health workers. AJOB Prim Res 1:45-54. doi:10.1080/21507716.2010.505898 
Schwartz L, Hunt M, Sinding C et al (2012) Models for humanitarian health care ethics. Public Health Ethics 5:81-90. doi:10.1093/phe/phs005

Slim H (1997) Doing the right thing: relief agencies, moral dilemmas and moral responsibility in political emergencies and war. Disasters 21:244-257

The Sphere Project Humanitarian Charter and Minimum Standards in Humanitarian Response (2010) Available at http://www.spherehandbook.org/ en/health-systems-standard-1-health-service-delivery. Accessed 04 Jan 2017.

Thoresen S, Tønnessen A, Lindgaard C et al (2009) Stressful but rewarding: Norwegian personnel mobilised for the 2004 tsunami disaster. Disasters 33: 353-368. doi:10.1111/j.1467-7717.2008.01078.x

United Nations Draft Declaration on Bioethics and Human Rights, UNESCO (2005) Universal Declaration on Bioethics and Human Rights. $33^{\text {rd }}$ session of the General Conference of UNESCO, Paris, 2005. Available via http://portal. unesco.org/en/ev.php-URL_ID=31058\&URL_DO=DO_TOPIC\&URL_SECTION= 201.html. Accessed 12 Oct 2016.

Walsh D (2009) Interventions to reduce psychosocial disturbance following humanitarian relief efforts involving natural disasters: an integrative review. Int J Nurs Prac 15:231-240. doi:10.1111/j.1440-172x.2009.01766.x

World Medical Association (2006) Statement On Medical Ethics In The Event Of Disasters. WMA General Assembly, Pilansberg, South Africa, October 2006 Available via http://www.wma.net/en/30publications/10policies/d7. Accessed 20 Oct 2016

\section{Submit your manuscript to a SpringerOpen ${ }^{\mathcal{O}}$ journal and benefit from:}

- Convenient online submission

- Rigorous peer review

- Immediate publication on acceptance

- Open access: articles freely available online

- High visibility within the field

- Retaining the copyright to your article

Submit your next manuscript at $\boldsymbol{s p r i n g e r o p e n . c o m ~}$ 